Jahrbuch für Geschichte Lateinamerikas

Anuario de Historia de América Latina

$57|2020| 190-225$

\title{
Florencia Guzmán
}

Instituto de Historia Argentina y Americana

"Dr. Emilio Ravignani"

UBA - CONICET

Identidades sociales y categorias raciales

en la era de la esclavitud y la

emancipación. El caso de Manuel

Macedonio Barbarín (Buenos Aires, 17921836)
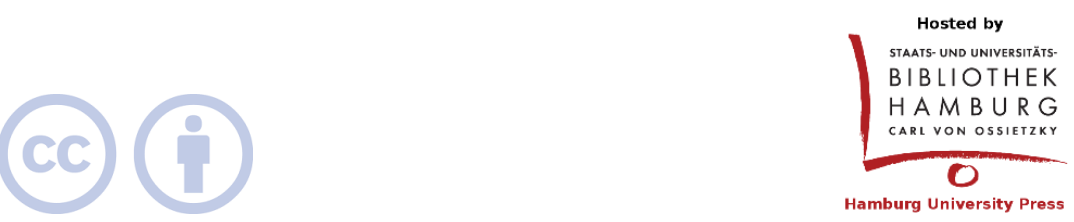

Except where otherwise noted, this article is licensed under a Creative Commons Attribution 4.0 International license (CC BY 4.0)

https://doi.org/10.15460/jbla.57.159 


\title{
Identidades sociales y categorías raciales en la era de la esclavitud y la emancipación. El caso de Manuel Macedonio Barbarín (Buenos Aires, 1792- 1836)
}

\section{Florencia Guzmán}

\begin{abstract}
In this article, the former slave Manuel Macedonio Barbarín will be used as a central theme in order to explore the social identities and racial categories reflected in the distinct spheres of the social experience of Africans and their descendants, enslaved and free, in the city of Buenos Aires during the final decades of the 18th century and the early 19th century. Through the reconstruction of small trajectories of individualization and collective actions I plan to investigate the complexities that social identities and racial categories assume from their different articulations and in their own historicity, that is to say in their specific contexts of temporality and specialty. The objective of this article is not to draw a biographical outline of the life of Manuel Barbarín, but to use his biography as an example in order to show the way in which urban experiences of slavery, emancipation, integration, otherness and social promotion were noted in the era of slavery and emancipation.
\end{abstract}

Keywords: Afrodescendants, City, Integration, Otherness, Social Promotion.

Resumen. - En este artículo propongo tomar a la figura de Manuel Macedonio Barbarín como hilo conductor con el objetivo de explorar las identidades sociales y las categorías raciales de los sectores de africanos y descendientes, esclavizados y libres, en la ciudad de Buenos Aires, durante las décadas finales del siglo XVIII y primeras del XIX. Con este objetivo planteo reconstruir pequeñas trayectorias de individuación y acciones colectivas para continuar indagando sobre las complejidades que asumen las identidades sociales y las categorías raciales a partir de sus diferentes articulaciones y en su propia historicidad, es decir en sus contextos específicos de temporalidad y espacialidad. No es el objetivo de esta investigación trazar un esbozo biográfico sobre Manuel Barbarín, sino hacer inteligible, a partir del mismo, la forma en la que se verificaron diversas experiencias urbanas de esclavitud, emancipación, integración, alteridad y promoción social en la era de la esclavitud y emancipación. 
Palabras clave: Afrodescendientes, ciudad, integración, alteridad, promoción social.

\section{Introducción}

Manuel Macedonio Barbarín nació en África y fue vendido como esclavizado en la ciudad de Buenos Aires en el año 1792 cuando tendría aproximadamente once años de edad. Una vez que alcanzó la libertad logró desarrollar una destacada actuación militar a lo largo de treinta años, y tras obtener el cargo de Teniente Coronel falleció el 3 de marzo de 1836. A consecuencia de su muerte, el periódico más importante de la ciudad, La Gaceta Mercantil, publicó varias semblanzas que resaltaban sus logros militares y también sus méritos como ciudadano. El redactor de una de ellas se refería a "un hombre de las circunstancias de Barbarín", aludiendo a su origen africano y a su condición de ex esclavo, la cual no le había impedido ascender en el escalafón militar e integrarse en la vida social de la ciudad. ${ }^{1}$

En el presente artículo propongo tomar a esta figura como hilo conductor con el objetivo de explorar las identidades sociales y categorías raciales, tal como se reflejaron en las distintas esferas de la experiencia social de los sectores de africanos y descendientes, esclavizados y libres, en la ciudad de Buenos Aires, durante las décadas finales del siglo XVIII y primeras del XIX.

Este trabajo se nutre y dialoga con una historiografía que integra la historia económica, la historia política y la historia social. Aquí destaco, en primer lugar, los aportes que provienen primordialmente del campo de estudios afrolatinoamericanos, en el cual una creciente producción de los últimos años ha sumado sus contribuciones al clásico y pionero libro del historiador Reid Andrews. En esas investigaciones se iluminan las complejidades que asumen los procesos de abolición de la esclavitud y sobre la caracterización que implican estos en el territorio del Rio de la Plata. ${ }^{2}$

\footnotetext{
${ }^{1}$ La Gaceta Mercantil, 24 de mayo de 1836, p. 2. El poema en el que se conmemora la vida de Barbarín fue publicado en el mismo periódico del 14 de marzo de 1836, p. 2.

2 Junto al libro de Reid Andrews, Los afroargentinos de Buenos Aires, Buenos Aires: Ediciones de la Flor, 1989, destaco las siguientes obras: Miguel Ángel Rosal, Africanos y afrodescendientes en el Río de la Plata. Siglos XVIII-XIX, Buenos Aires:
} 
En otra serie de investigaciones prevalece el interés por conocer mejor el mundo de la plebe urbana donde el peso de la esclavitud fue significativo. El historiador Lyman Johnson, quien pone en el centro de la escena el mundo del trabajo, procura echar luz sobre la forma en que las vidas de los sectores plebeyos se vieron afectadas por las poderosas e imponentes fuerzas que transformaron el mundo del Atlántico a fines del siglo XVIII y a principios del XIX. ${ }^{3}$ Su aporte resulta inestimable para estudiar las numerosas intersecciones que surgen en el estudio de la inmigración libre, el tráfico de esclavizados africanos, la organización del trabajo y los violentos comienzos de la era revolucionaria.

Un tercer grupo de trabajos se ha focalizado en el proceso independentista y en las acciones de la plebe durante la guerra desencadenada por la revolución en 1810. Para el historiador Tulio Halperin Donghi, la guerra y la extendida militarización que devino de la misma implicó un cambio en el equilibrio social y político de Buenos Aires. ${ }^{4}$ Para el autor, la guerra no solamente allanó el camino hacia la abolición de la esclavitud, sino que además produjo una serie de

Durken, 2009; Silvia Mallo / Ignacio Telesca (eds.), Negros de la patria. Los afrodescendientes en las luchas por la independencia en el antiguo virreinato del Río de la Plata, Buenos Aires: SB, 2010; Alex Borucki, De compañeros de barco a camaradas de armas. Identidades negras en el Río de la Plata. 1760-1860, Buenos Aires: Prometeo Libros, 2017; Peter Blanchard, Under the Flags of Freedom. Slave Soldiers and the Wars of Independence in Spanish South America, Pittsburgh: University of Pittsburgh Press, 2008; Florencia Guzmán, “Afroargentinos, guerra y política, durante las primeras décadas del siglo XIX. Una aproximación hacia una historia social de la revolución": Estudios Históricos, 11 (2013). Trabajos recientes en esta dirección incluyen los de Magdalena Candioti, Un maldito derecho. Leyes, jueces y revolución en la Buenos Aires republicana. 1810-1830, Buenos Aires: Ediciones Didot, 2017 y Magdalena Candioti, “'El tiempo de los libertos'. Conflictos y litigación en torno a la ley de vientre libre en el Río de la Plata (1813-1860)": História (São Paulo), 38 (2019), pp. 1-28; Florencia Guzmán, “¡Madres negras tenían que ser! Maternidad, emancipación y trabajo en tiempos de cambios y transformaciones (Buenos Aires, 1800-1830)": Tempo, 24: 3 (2018), pp. 450-473; Florencia Guzmán / María de Lourdes Ghidoli (eds.), El asedio a la libertad. Abolición y post-abolición de la esclavitud en el Cono Sur, Buenos Aires: Editorial Biblos, 2020.

3 Lyman Johnson, Los talleres de la revolución. La Buenos Aires plebeya y el mundo del Atlántico. 1776-1810, Buenos Aires: Prometeo Libros, 2013, pp. 19-35.

4 Tulio Halperín Donghi, Revolución y guerra. Formación de una elite dirigente en la Argentina criolla, Buenos Aires: Siglo Veintiuno, 1994 (1972), pp. 140-143. 
innovaciones de distinta naturaleza que llegaron a tener efectos duraderos en los modos de sociabilidad del conjunto de la población. Investigaciones más recientes, como la de los historiadores Gabriel Di Meglio y Raúl Fradkin, se han centrado más detenidamente en el accionar y en las características de la participación política y militar de los sectores plebeyos durante el periodo independentista. ${ }^{5}$ En este caso la 'plebe urbana' es definida como un heterogéneo conjunto de personas, que étnica y ocupacionalmente, compartían un lugar subordinado en la sociedad, además de tener en común su pobreza material, la mayoría de sus costumbres y ciertos espacios de sociabilidad. Si bien la mayor cantidad de estudios se ha ocupado de la llamada época de la revolución, también puede advertirse una tendencia a examinar con mucho mayor cuidado las formas de acción y experiencias de movilización política de las décadas postrevolucionarias, sobre todo en las criticas décadas de 1830 y 1849, sin las cuales, tal como afirma Raúl Fradkin, serían incomprensibles los procesos de abolición. ${ }^{6}$

Por último, una temática particularmente significativa para esta investigación es la que pone el foco en las representaciones e identidades sociales vinculadas con la militarización y la abolición de la esclavitud. Si bien estas cuestiones han sido analizadas - en mayor o menor medida- por los autores mencionados anteriormente y por otros investigadores que también analizan las identidades sociales en la ciudad de Buenos Aires, ${ }^{7}$ sería recién a partir del libro de Alex Borucki

5 Gabriel Di Meglio, ¡Viva el bajo pueblo! La plebe urbana de Buenos Aires y la política entre la Revolución de Mayo y el Rosismo, Buenos Aires: Prometeo Libros, 2006; Raúl O. Fradkin (ed.), ¿Y el pueblo dónde está? Contribuciones para una historia popular de la revolución de independencia en el Río de la Plata, Buenos Aires: Prometeo Libros, 2008; Daniel Santilli / Jorge Daniel Gelman / Raúl 0. Fradkin (eds.), Rebeldes con causa. Conflicto y movilización popular en la Argentina del siglo XIX, Buenos Aires: Prometeo Libros, 2013 y Raúl O. Fradkin / Gabriel Di Meglio (eds.), Hacer política. La participación popular en el siglo XIX rioplatense, Buenos Aires: Prometeo Libros, 2013.

6 Raúl O. Fradkin, "De síntomas e interpelaciones”: Guzmán / Ghidoli. (eds.), El asedio a la libertad, p. 20.

7 Un estudio comparativo entre las ciudades de Córdoba y Buenos Aires referido a las prácticas matrimoniales es revelador de las identidades sociales y raciales diferenciales entre estas ciudades. Susan Migden Socolow, "Parejas bien 
cuando las identidades negras se convierten en el centro de su investigación. El estudio de cómo operaban los individuos en diferentes ámbitos le permite al autor construir una interpretación más completa y compleja de la formación de las identidades sociales. Según Borucki, los barcos esclavistas, las cofradías católicas negras, las asociaciones de base africana y los batallones de negros no estaban aislados entre sí, sino que, en tanto campos de experiencia, constituyeron los hilos a través de los cuales los africanos y sus descendientes tejieron sus propias identidades que les permitieron interactuar con los sectores dominantes de la sociedad. ${ }^{8}$

En la investigación que procuro llevar adelante postulo que un análisis histórico extendido en el tiempo me da la posibilidad de reconstruir pequeñas trayectorias de individuación y acciones colectivas para continuar indagando sobre las complejidades que asumen las identidades sociales y raciales en la era de la esclavitud y emancipación. No es el objetivo de esta investigación trazar un esbozo biográfico sobre Manuel Barbarín, sino hacer inteligible, a partir del mismo, las articulaciones y cruces entre aspectos sociales, jurídicos y raciales y las redes forjadas entre individuos concretos. Con esta finalidad, en las páginas que siguen delimitaré tres procesos consecutivos - una especie de tres actos de una obra teatral- en los cuales Barbarín fue testigo y actor. El primero de ellos está situado a fines del siglo XVIII y coincide con su condición de esclavizado. El segundo momento combina con su emancipación y con el inicio y desarrollo de su carrera militar y familiar. En tercer lugar, y por último, asistimos a la consagración de la carrera militar y a su promoción social que forma parte del periodo del gobierno que encarna y lidera Juan Manuel de Rosas.

\section{Ser esclavizado en la ciudad porteña}

Las biografías realizadas sobre Barbarín coinciden en señalar su procedencia africana e incluso mencionan al pueblo de Calibali (Angola) como su lugar de origen. También establecen su arribo a Buenos Aires

constituidas. La elección matrimonial en la argentina colonial (1778-1810)": Anuario del IEHS, 5 (1990), pp. 133-160.

8 Alex Borucki, De compañeros, p. 16. 
en 1792, cuando tenía 11 años de edad. ${ }^{9}$ De modo que fue uno de los miles de esclavizados introducidos en la ciudad de Buenos Aires luego de que se estableció la Real Cédula de Libre comercio de negros del año 1791, que en la práctica significaría la mayor importación de esclavos en el espacio rioplatense. Esta situación originó que entre 1790 y 1800 se diese un explosivo crecimiento en el comercio trasatlántico, arribando 18.283 esclavizados a Montevideo y a Buenos Aires, desde Brasil y África. ${ }^{10}$ A partir de ese momento, tanto Manuel Macedonio, como el resto de los afrodescendientes esclavizados y libres, pasaron a constituir una presencia dominante en las calles y en los espacios públicos de la ciudad y sobre todo fueron el sostén central de la economía local.

Esta ciudad, por su crecimiento económico y expansión comercial dependía de las continuas corrientes de migrantes internacionales, regionales y también de la mano de obra esclavizada.

Sucedía que la ciudad de Buenos Aires había crecido considerablemente y en gran medida esta evolución derivó de la apertura del puerto, que se convirtió en el principal puerto del Atlántico del comercio de ultramar en la región sur del imperio. La población se había cuadriplicado como consecuencia al ingreso de esclavizados

\footnotetext{
${ }^{9}$ Considerando que se menciona el año 1781 como la fecha de nacimiento. Este dato y otros que se expondrán concernientes a la carrera militar de Manuel Macedonio fueron extraídos de una semblanza publicada en la Gaceta Mercantil, el 24 de mayo de 1836, y firmada por "un federal amigo del difunto Teniente Coronel Barbarín". Según el autor anónimo se valió para el escrito de "documentos originales" que creía oportuno publicar para que se conociese de la vida de "este oficial benemérito, algo más detallado que las noticias que sobre ello se realizaron en los últimos días [...]”. Esta semblanza ha sido tomada como referencia en todas las biografías que se realizaron sobre Barbarín. Por ejemplo: Jacinto Yaben, Biografías argentinas y sudamericanas, Buenos Aires: Editorial Metrópolis, 1938, vol. 1, pp. 118-119; Vicente Osvaldo Cutulo, Nuevo diccionario biográfico argentino, Buenos Aires: Editorial Elche, 1968, p. 141; Marcos de Estrada, Argentinos de origen africano, Buenos Aires: Eudeba, 1979, p. 230. En ninguno de estas biografías se citan las fuentes por lo que recurriré a ellas como referencia solamente cuando no tenga otra documentación que acredite los hechos.

10 El 84\% de los esclavizados que llegaron al Río de la Plata entre 1777 y 1812 fueron desembarcados después de la normativa de 1792. Según la reconstrucción minuciosa realizada por el historiador Alex Borucki, a partir de esa fecha en adelante hubo un aumento de esclavos hasta 1807 cuando la crisis política afectó el trabajo colonial. Borucki, De compañeros, p. 50.
} 
proveniente de África, así como de una permanente inmigración libre procedente de Europa y del interior del virreinato del Río de la Plata, que fue cambiando significativamente la constitución social, étnica y racial de la ciudad. ${ }^{11}$ Manuel Macedonio convivía a diario con esclavizados criollos y nativos africanos, y con sujetos libres clasificados como blancos, negros, pardos, morenos, indios y mestizos. ${ }^{12}$

¿Por qué resulta tan importante enfatizar el desenvolvimiento de la ciudad de Buenos Aires al momento que Barbarín se convierte en uno de los tantos esclavizados que ingresaron y vivieron en la misma? Porque las transformaciones que vivió la urbe porteña la ubicaron en un lugar de gran significación en el circuito del Atlántico sur y porque los permanentes ingresos de población coadyuvaron en la conformación de una sociedad móvil y en una nueva cristalización de las jerarquías raciales y sociales que la fueron diferenciando del resto de los espacios coloniales rioplatenses. ${ }^{13}$ La libertad comercial a la que se hizo referencia significó además de un incremento considerable del comercio internacional, un flujo de noticias e ideas. Los barcos que llevaban charqui, carne seca y salada, uno de los puntales de la expansión comercial rioplatense, a Brasil, a Cuba, y a otras islas del Caribe, -Santo Domingo, Puerto Rico- se manejaban con tripulaciones mixtas de esclavizados y marineros libres que traían las novedades sobre las revoluciones. Desembarcados en el puerto de sus viajes trasatlánticos las versiones se expandían por toda la ciudad hasta el interior más profundo. Es el sector móvil -peones, jornaleros, migrantes y comerciantes minoristas - el que lleva la voz cantante haciendo las veces de informales cronistas de la política internacional. Como afirma el historiador Lyman Johnson, las noticias provenientes de Santo Domingo y de Francia contribuyeron al carácter xenofóbico

11 El censo de 1810 registró 9.615 negros y mulatos en una población de 32.558 personas (es decir un 29 por ciento). Es importante aclarar que tanto los escritos de los contemporáneos como una serie de investigaciones que toman como referencia los censos de población coinciden en señalar un sub-registro de la población de ascendencia africana. Sobre este tema véase Johnson, Los talleres de la revolución, pp. 63-64.

12 Johnson, Los talleres de la revolución, pp. 60-79.

13 Sobre el alcance de estas transformaciones remito al clásico libro de Halperín Donghi, Revolución y guerra, pp. 15-75; Johnson, Los talleres de la revolución, pp. 37-80; Socolow, Parejas bien constituidas, pp. 133-160. 
imperante en la ciudad. En Haití se había llevado a cabo la única revolución de esclavos triunfante en el mundo y la primera independencia de América Latina. Si bien las noticias que llegaban de Santo Domingo aumentaban el miedo local a la violencia de los esclavos y la muerte de los amos en manos de éstos, las imágenes de la revolución francesa y de los ataques anticlericales a la Iglesia Católica se comentaban en todos los rincones de la ciudad de Buenos Aires. ${ }^{14}$

En este escenario de profundas transformaciones había comenzado a transitar sus primeros años Manuel Macedonio, vinculado a un comerciante europeo, cuya relación va a tener importantes consecuencias a lo largo de su vida. Se trata de Juan Barbarín, de origen francés, quien al comprarlo le dio el nombre de Manuel Macedonio Barbarín. A los tres años de estar en la ciudad ambos se vieron involucrados en la sospecha de una supuesta insurrección de extranjeros que buscaban incitar una rebelión de esclavos. ${ }^{15}$ Diferentes testigos señalaron a Barbarín como uno de los jóvenes franceses sospechosos de la presunta insurrección que debía llevarse a cabo en la semana santa del año 1795. Ante el cúmulo de rumores, el virrey Nicolás

\footnotetext{
14 Johnson, Los talleres de la revolución, pp.19-36.

15 Tomo como referencia dos expedientes judiciales de los varios que produjo la investigación. El primero abarca el cuerpo de la investigación: "Pesquisa general sobre la sublevación intentada hacer por Negros y Franceses en esta capital de Buenos Aires", Archivo General de la Nación [AGN]. División colonia. Sección gobierno. Interior, 1795, Legajo 32; el segundo refiere a la defensa realizada por Juan Barbarín: “Criminales, autos seguidos contra Juan Barbarín”, Archivo Histórico de la Provincia de Buenos Aires, La Plata. Archivo de la Real Audiencia, leg. 104, exp. 11, año 1795. Además, esta investigación suscitó una serie de publicaciones. Entre ellas destaco el trabajo minucioso de Ricardo R. Caillet-Bois, Ensayo sobre el Río de la Plata y la revolución francesa, Buenos Aires: Facultad de Filosofía y Letras, 1929 (apéndice 110.11). Asimismo, Exequiel César Ortega, El complot colonial. 1795. Año de procesos, tortura y brindis por la libertad, Buenos Aires: Editorial Ayacucho, 1947; Boleslao Lewis, "'La conspiración de los franceses' en Buenos Aires (1795)": Anuario del Instituto de Investigaciones Históricas, 4: 4 (1960), pp. 9-57; Norma Bueno, Conspiración de esclavos en el Río de la Plata en 1795, Buenos Aires: Biblos, 1990; María Verónica Secreto, "Sediciosa Buenos Aires. O complot de franceses e escravos no Rio da Prata": Historia Unisinos, 17: 2 (2013), pp. 158-167 y María Verónica Secreto, "Brindes, textos e libros prohibidos. A 'conspiraçao de escravos e franceses' na Buenos Aires colonial”: Revista Outros Tempos - Pesquisa em Foco, 11: 18 (2014), pp. 188-207; Johnson, Los talleres de la revolución, pp. 329-334.
} 
Antonio de Arredondo emprendió una investigación que puso a cargo de don Juan Martín de Álzaga, genuino representante del pensamiento político español y miembro del Cabildo de Buenos Aires.

La investigación fue sumamente importante para este trabajo porque provee pistas sobre la composición social y racial de la ciudad y lo ubica a Manuel Barbarín en el medio de las experiencias atlánticas e interrelaciones de movimientos y revoluciones. ${ }^{16}$ La pesquisa se dio en un clima de rumores y de temor por una serie de pasquines distribuidos en los principales puntos de la ciudad que hablaban de 'libertad'. Esta atmósfera se reavivaba por algunos factores externos e internos, y por los fuertes recelos en el orden local, originado en el crecimiento considerable de la población esclavizada en la ciudad y a rasgos de beligerancia y agresividad atribuida a la misma. Lyman Johnson le otorga asimismo importancia al malestar que generaba en los sectores plebeyos el alza de precios en ciertos bienes básicos, como el trigo, que generaba en la opinión pública porteña sospechas y reacciones sobre los panaderos franceses, a quienes se los responsabilizaba de la manipulación del mercado de trigo. ${ }^{17}$ Sucedía que, como afirma este autor, en esta "geopolítica del miedo", detrás de cada francés se veía a un conspirador, un ateo, un jacobino, un subversivo. ${ }^{18}$

La investigación recayó en una pequeña comunidad porteña de residentes franceses, integrada mayoritariamente por un puñado de comerciantes mayoristas y minoristas involucrados en el comercio atlántico, entre los que se encontraba don Juan Barbarín. Durante los meses que duró la pesquisa, cientos de testigos y sospechosos desfilaron por las oficinas del Cabildo: entre ellos, el relojero Santiago Antonini (italiano), el pulpero don Ignacio López (porteño), el panadero Juan Luis Dumonte (francés), el zapatero Manuel Antonio Sustaíta (porteño), el sastre Andrés Despland (francés), el panadero Juan Antonio Gallardo (francés), el pulpero Juan Polovio (francés), el escribiente Pablo Mayllos y Marcana (francés). En todos los casos

\footnotetext{
${ }^{16}$ Como lo explica Verónica Secreto, los documentos sobre la investigación de 1795 permiten reconstruir un mundo de conexiones en el atlántico y en América, evidenciando espacios y conexiones frecuentemente marginalizadas en los análisis. Secreto, "Sediciosa Buenos Aires", p. 189.

17 Johnson, Los talleres de la revolución, p. 213.

18 Ibidem, pp. 209 y 210.
} 
aparece el detalle de la procedencia (región de origen) y sobre todo la actividad laboral que desarrollaban.

¿Quién era Juan Barbarín? Como ya se ha dicho, era un comerciante de origen francés, de 38 años, soltero, que había llegado al Río de la Plata diez años atrás. Su origen galo y algunas manifestaciones públicas a favor del nuevo orden establecido en Francia, sumado a su deseo también público- de que España continuase en este camino lo llevaron a ser considerado como uno de los principales sospechosos. Se lo acusaba de realizar en su domicilio "juntas de franceses" en las que se brindaba por la libertad. Además de sus actividades comerciales, ejercía el cargo de Síndico de la Hermandad de San Benito, que debía adminstrar la recaudación de limosnas que le traían los hermanos "negros"19 empleados en las calles con ese objeto. Según algunos testigos, estos "negros" entraban y salían de su casa con regularidad y en total libertad. Varios de los interrogados sobre sus movimientos y sus relaciones en la ciudad señalaron su honradez y sus buenos hábitos. Algunos se refirieron de manera particular al comportamiento del comerciante francés con el esclavo Manuel con quien tenía las mayores "demostraciones de cariño y amor". Y — como alguien declaró- si bien esta actitud no le había resultado "peligrosa", ahora, a la vista de los hechos no dejaba de llamarle la atención. ${ }^{20}$

Un sargento perteneciente a la guarnición militar local informaría a Álzaga que en numerosas ocasiones había visto que Barbarín y su esclavo Manuel caminaban por la orilla del río durante las horas de la siesta. Interrogado por el alcalde sobre que significación tendría este hecho, este informante señaló que en estas horas del día eran muy pocos los que transitaban por la calle y que llamaba la atención la despreocupación de ambos cuando caminaban por allí. ¿Cuál pudo haber sido el tema de las conversaciones secretas entre amo y esclavo?, se preguntaba el testigo. ¿Cómo podía ser que un comerciante respetado pudiera salir a la hora de la siesta, horario reservado para la sociabilidad popular y de mal gusto, según el criterio de la gente 'decente'? La pregunta refiere a las jerarquías raciales y sociales vinculadas con el espacio y las prácticas urbanas finiseculares.

Cuando fue interrogado Juan Barbarín, éste declaró una serie de estrategias para alejarse de los recelos que originaba su procedencia

${ }^{19}$ El entrecomillado remite en todos los casos al término racial textual en la fuente. 20 "Pesquisa general", AGN, f. 13. 
francesa. ${ }^{21}$ La primera de ellas había sido su cambio de identidad, pues su verdadero nombre era Juan Pablo Capdepón y provenía de Santa María, Reino de Navarra, la Baja. Se crió en Valencia (España) desde los 11 años y al pretender salir de Cádiz para Buenos Aires, un conocido don José de Guruchaga - le aconsejó cambiar su identidad francesa por una española. Esto fue lo que hizo a través de una fe de bautismo que le proporcionó una nueva identidad como Juan Barbarín. La segunda de ellas tenía que ver con el cumplimiento y visibilización de la ritualidad religiosa. En referencia a ello declaró su filiación católica y su integración a la Hermandad de San Benito como ya se dijo, de la tercera orden de San Francisco, además de figurar en los libros parroquiales de bautismo como padrino de tres ahijados que había tenido en estos años. Según su declaración le trasmitía a su criado su religiosidad en tanto leía con él a Fray Luis de Granada 22 y otros libros de devociones, "nunca gacetas". ${ }^{23}$ Con referencia a su "criado" Manuel dijo que le había enseñado a leer y escribir $\mathrm{y}$, luego, para que se perfeccionase su escritura - con la idea de que le copiase cartas de su correspondencia y le escribiese otras cosas que necesitaba- había contratado a un inmigrante francés de 28 años, llamado Pablo Mayllos y Marcana, quien había llegado a la capital hacía tres años. Mayllos desde su arribo a Buenos Aires trabajaba como "escritor de cartas" y con frecuencia armaba una pequeña mesa en la Plaza Mayor o cerca del Cabildo donde escribía cartas para clientes, a parientes lejanos o a autoridades y empleados públicos de otras ciudades. ${ }^{24}$ Juan Barbarín le ofreció el generoso salario de cuatro pesos por mes para brindarle instrucción privada al esclavo. Incluso, cuando esta relación se profundizó, Mayllos se quedó en alguna ocasión en la casa de Barbarín como invitado, ingresando al círculo social del comerciante. ${ }^{25}$

¿Por qué esta relación entre amo y esclavo los convertía a ambos en sospechosos? En el caso de Juan Barbarín demostraba un desconocimiento de la jerarquía y de la distancia que debía existir entre el criado y el amo, situación que subvertía un principio ordenador de la

21 “Pesquisa general”, AGN, Declaración de Juan Barbarín, fs. 63 a 67.

22 Fray Luis de Granada, español (1504-1588), fue un escritor dominico, que escribió varios libros de retórica eclesiástica.

23 "Pesquisa general", AGN, f. 63.

24 Caillet-Bois, Ensayo sobre el Río de la Plata, p. 88.

25 "Pesquisa general", AGN, f. 65. 
sociedad colonial. Un segundo problema que arrastraba esta relación, inapropiada para los patrones de la época, era la visibilidad de la misma, a la vista de todo el vecindario. Ambas cuestiones, no solamente constituían una transgresión a las reglas coloniales, sino que además importaban el peligro de ser imitada. Pero, sobre todo, a juzgar por el interrogatorio, lo más peligroso fue la decisión de Juan Barbarín de contratar un maestro para que le enseñara a su esclavo a leer y escribir. ¿Podía un esclavo gozar de este privilegio?

De manera que Mayllos y el esclavizado Manuel no tardaron en seguir a don Juan en la prisión. El origen francés de Mayllos y la calidad de escribientes de ambos, en una sociedad mayoritariamente iletrada, le dieron a Álzaga suficientes motivos para considerarlos sospechosos de ser los autores de los pasquines revolucionarios que se hallaban distribuidos en los distintos puntos de la ciudad. Manuel en su declaración admitió las caminatas junto con su amo a la hora de la siesta y reconoció que aquél lo trataba con "amor" y que lo vestía bien. ${ }^{26}$ Afirmó además que su amo jamás hablaba sobre las revoluciones de Francia ni de Santo Domingo. Dijo, asimismo, que éste le había prometido la libertad, solamente en el caso de que ese se volviese a España o luego de su muerte, si esta ocurría en Buenos Aires. Ante la pregunta del porqué Juan Barbarín quería que aprendiese a leer y escribir, Manuel contestó que aquél necesitaba que le llevara las cuentas de su negocio para poder quedarse a cargo cuando los compromisos de su amo se lo exigieran. Por último, ante la pregunta de Álzaga sobre qué leía, éste contestó que "solo cuentas y cartas relacionadas con los negocios del amo"; pero agregó que aquel estaba dispuesto a leerle "cualquier libro" para que avanzara en su instrucción.27

La situación de letrado de Manuel y su experiencia laboral y residencial contrastaba con la de otros esclavizados y libres, varones y mujeres, que también declararon en el proceso judicial. Algunos encontraron en el clima de rumores y de miedo un relato de resistencia y autonomía. La "negra" esclava de doña María Josefa Gauto amenazó que no pasaría mucho tiempo en el que la verían vestida como la mejor de la ciudad. Esta habría afirmado "de que se rían, ya lo verán". ${ }^{28} \mathrm{Un}$ "mulato" llamado Martín llegó junto a un "negro" de San Francisco a la

26 Ibidem, fs. 20-22.

27 "Pesquisa general”, AGN, fs. 20-22.

28 Ibidem, f. 11. 
pulpería de don Ignacio López, y recostándose sobre el mostrador afirmó: "Ahora ya lo verán los criollitos y los españoles que le hemos de hacer con los franceses". ${ }^{29} \mathrm{Un}$ "moreno" esclavo de nombre José Albariño, ante las provocaciones e insultos de sus compañeros había amenazado "que el Viernes Santo los esclavos de la ciudad ajustarán cuentas". 30

El "negro" Pedro fue todavía más lejos de estas bravuconadas. Acusó a su amo Luis Dumonte, un panadero francés, de ser uno de los organizadores de la conspiración. Dumonte se había embarcado en Cádiz en calidad de criado y una vez en Buenos Aires trabajó primero en una panadería y luego terminó alquilando su propio negocio. ${ }^{31}$ En esta fábrica de pan trabajaba Pedro, africano, quien había sido comprado en Rio de Janeiro por un oficial de artillería. El esclavizado se presentó ante Álzaga para delatar a su amo, seguramente en venganza de los cepos y grillos a los que éste lo sometía. De la declaración de Pedro se desprende que entre el propietario y el esclavizado había una relación de amenazas, violencias y reiterados tormentos. En su afán de incriminarlo, Pedro dio varios datos que podían comprometerlo. En primer lugar, afirmó que en la casa de Dumonte se realizaban "juntas de franceses" que duraban varias horas - desde las dos hasta las seis de la tarde-, a las que asistían todos extranjeros que brindaban por la "libertad". 32 En segundo lugar, inculpó a su amo de tener varias armas en su domicilio - tres trabucos, una espada, una lanza, una cuchilla ancha. En defensa del acusado el abogado justificó las armas que se encontraron en el domicilio del panadero en el clima de violencia e intimidación extrema que se vivía con y entre los obreros de esta fábrica. Según el letrado, el "negro" Pedro, que había venido de Guinea, había pasado por varias prisiones por diferentes acciones de violencia contra sus propietarios: a uno lo quiso matar y a otro envenenar. El apoderado describió una situación concreta: ocho días antes de la prisión de Dumonte éste le había levantado una plancha de hierro y unos grilletes que le tenía puesto en una pierna y que le impedían caminar. ${ }^{33}$

\footnotetext{
29 Ibidem, f. 36.

30 Johnson, Los talleres de la revolución, p. 222.

31 Caillet-Bois, Ensayo, pp. 80-82.

32 Caillet-Bois, Ensayo, pp. 80-81.

33 Ibidem, p. 97.
} 
De los dichos de Pedro y de otros testigos surgen diferencias importantes en relación a las trayectorias laborales de los afroporteños en la ciudad. Manuel, como otros esclavizados que operaban en el mercado laboral local y que gozaban de cierto grado de autonomía de los amos, se había integrado al tejido urbano incluso mejor que algunos migrantes pobres provenientes del interior del virreinato que carecían de las redes necesarias para insertarse en la ciudad. Estas redes, además de proveer protección, resultaban cruciales para la actividad diaria de buscar trabajo y asegurarse el sustento. Podían, incluso, llegar a cambiar la vida de los sujetos de manera impredecible. ${ }^{34}$ Prueba de ello será la resolución final del proceso. Luego de seis meses de investigación en la que no se pudo comprobar la conspiración, el 10 de setiembre de ese año, Álzaga emitió el veredicto. En el mismo sentenció a Juan Barbarín y a todos los extranjeros a exiliarse en España y a la confiscación de sus bienes. El dictamen en la práctica no se cumplió, habida cuenta de que varios de ellos siguieron actuando en la capital en la década siguiente. La pena mayor recayó en José Díaz, un migrante de Corrientes, casado, de 62 años, quien había sido torturado varias veces. Le correspondieron diez años en prisión en las desoladas islas Malvinas y luego unos años en la ciudad. Díaz, que había vivido en Buenos Aires durante una década, fue identificado en el proceso judicial de varias maneras: como "mestizo" o "mulato", aunque él se refirió asimismo como "moreno". 35 ¿De qué se lo acusaba? Según el esclavizado de José Alvariño, aquél le habría dicho que ya se acercaba el tiempo de tomar venganza, que estuviera preparado para el levantamiento de "Franceses, Mulatos, Indios y Negros" que les daría la libertad de todos. También agregó que los indios habrían de "venir libertando a Negros y Mulatos". 36

De modo que la investigación sobre una presunta conspiración destinada a generar una rebelión de esclavos en Buenos Aires ofrece

\footnotetext{
34 Johnson, Los talleres de la revolución, pp. 37 y 38.

35 Sobre la variabilidad y ambigüedad de las designaciones de "castas" en el Rio de la Plata véase Florencia Guzmán, "Performatividad social de las (sub)categorías coloniales. Mulatos, pardos, mestizos y criollos en tiempos de cambios, guerra y política en el interior de la Argentina": Florencia Guzmán / Lea Geler, Cartografías afrolatinoamericanas. Perspectivas situadas para análisis transfronterizos, Buenos Aires: Biblos, 2013, pp. 57-86.

36 Caillet-Bois, Ensayo, p. 95.
} 
intensas articulaciones con los cambios demográficos y sociales que habían transformado la plebe de Buenos Aires y la población de ascendencia africana de manera particular. Se percibe cómo la economía de la ciudad capital y la población se movía recíprocamente al ritmo de los sucesos que se producían en el Atlántico. La presencia de comerciantes europeos, franceses e italianos, que levantaban con frecuencia sus copas para brindar por la libertad, sintetizan en parte el lugar que ocupa la ciudad puerto de Buenos Aires e incluso la tensión entre lenguajes y representaciones del Antiguo Régimen y la modernidad.

En torno a las identidades sociales el análisis referido no sugiere una experiencia única y uniforme para los esclavizados, descendientes libres y trabajadores plebeyos. Más bien se advierte la índole maleable y compleja de las identidades de clase y raciales en este entorno preindustrial. Las categorías racializadas y ocupacionales están presentes en todo el cuerpo de la investigación y se exponen y despliegan en una variedad de términos, tanto de parte de las autoridades, como de entre los mismos plebeyos para definir a los otros y para referirse a sí mismos (pulpero, zapatero, relojero, cocinero, panadero, soldado; asimismo negro, mulato, moreno, mestizo). Las declaraciones de los testigos y acusados reflejan asimismo una habilidad para la observación social, atentos a la diferencia y la jerarquía.

En este contexto, el "criado" "negro" Manuel Barbarín era un esclavizado que había nacido en África y había alcanzado cierto nivel de respetabilidad ante sus juzgadores, pero también recelos. Su condición de letrado adquirirá una nueva gravitación con el correr de los años.

\section{Guerra de Independencia y emancipación}

La primera década del siglo XIX se inició con cambios significativos en la vida de Manuel. El 19 de octubre de 1805 contrajo matrimonio con Simona Sarratea, natural de la ciudad y "esclava que fue de D. Martín de Sarratea", suegro de don Santiago de Liniers y uno de los comerciantes más importantes de ese momento. En la parroquia de La Merced, consagró el matrimonio el Presbítero D. Juan Manuel Giménez quien dejó registrada en el libro de "Pardos y Morenos" la unión de los "negros libres", luego de que se realizaron las proclamas conciliares, de verificar 
que no hubiese impedimento canónico y tras haberse otorgado "sus mutuos consentimientos". ${ }^{37}$

Hasta el momento no he hallado el documento del otorgamiento de la libertad de Manuel, lo cual no me permite conocer la modalidad de la manumisión: si ésta fue otorgada por el propietario francés o si la misma derivó del trabajo y ahorro de parte del esclavizado. Sí queda claro a través del registro eclesiástico que al momento de contraer enlace ambos cónyuges eran de condición libre, lo cual refuta la afirmación reproducida en todas las biografías de Manuel de que obtuvo la libertad como premio por su actuación en las invasiones inglesas de 1806 y 1807.

Esta acción y esta fecha se establecen como un hito del cambio y transformaciones que va a vivir la ciudad y todos sus habitantes. El primer escenario se manifestó en 1806 cuando una pequeña fuerza británica liderada por William Beresford logró dominar la capital. Buenos Aires capituló y la bandera británica fue izada el día 28 de junio en el fuerte, donde flameó durante 46 días. Finalmente, la ciudad logró ser reconquistada por la labor mancomunada de soldados y milicianos, por un lado, y de sus habitantes, por otro. El mismo escenario se dio al año siguiente cuando regresó una nueva fuerza británica. Las unidades de milicias y de voluntarios derrotaron una vez más a los ingleses en julio de 1807, siendo Martín de Álzaga y Santiago de Liniers los líderes indiscutidos de estas jornadas. ${ }^{38}$

La victoria final revistió a la capital de una sensación de grandeza y de embriaguez. Una prueba simbólica de esta euforia fueron los cambios en la nomenclatura en la ciudad. La Plaza Mayor se convirtió en 'Plaza de la Victoria', el Retiro pasó a ser el 'Campo de la Gloria' y la plaza de Monserrat se rebautizó 'Fidelidad' debido a la acción destacada de los esclavizados. ${ }^{39}$ El día 12 de noviembre de 1807, en un acto público, y

\footnotetext{
37 Secretaría de Rosas, AGN, X, 25-3-1. Con fecha 9 de abril de 1836 el Cura Rector de la Catedral en la Merced certifica que en el libro de matrimonios de "Pardos y Morenos", que empieza en julio de 1801 y concluye en setiembre de 1818, en el folio 41, se encontraba la partida de matrimonio de Manuel Macedonio y Simona Sarratea.

38 Para conocer más sobre el tema remito a Peter Blanchard, "An Institution Defended. Slavery and the English Invasions of Buenos Aires in 1806-1807": Slavery \& Abolition, 35:2 (2014).

39 Di Meglio, ¡Viva el bajo pueblo!, p. 5.
} 
con una gran ritualidad, tuvo lugar en la Plaza de la Victoria la primera fiesta patriótica de Buenos Aires. En esta ocasión se les dio la libertad a 130 esclavizados en reconocimiento al heroísmo y altruismo puesto de manifiesto en la lucha contra los ingleses. ${ }^{40}$

El segundo escenario que debemos considerar tiene que ver con el quiebre del orden colonial y el establecimiento de una nueva legitimidad política. Al estallar el movimiento del 25 de mayo de 1810, los revolucionarios rioplatenses pudieron contar con milicias inusualmente poderosas, reclutadas para resistir a los ingleses, que les permitió disponer de un brazo armado fuerte y decidido. Esta ventaja inicial respecto a otros espacios latinoamericanos se expresó en la decisión con que la junta de gobierno se lanzó a la guerra, formando grandes ejércitos y multiplicando los teatros de operaciones a cientos de kilómetros de la capital, todo lo cual derivó en una amplia movilización y en una extensa militarización de la sociedad. ${ }^{41}$

Para este periodo, Manuel Macedonio, como la mayoría de la población masculina adulta, se encontraba militarizado. Junto con él ingresaron a las milicias y a las fuerzas militares regulares cientos de artesanos, obreros, jornaleros y peones de ascendencia africana. En 1807, Manuel integró el Batallón de Castas, y en su condición de sargento de morenos fue distinguido por el virrey Cisneros con una medalla de plata por "su conducta marcial" en la defensa de Buenos Aires. ${ }^{42}$ En 1810 alcanzó el grado de capitán de milicias de aquel cuerpo, de modo que en muy poco tiempo había superado un límite de ascenso para la mayoría de los plebeyos que debían conformarse con el cargo de sargento segundo. 43

Previsiblemente, saber leer y escribir era una condición necesaria para ascender y lograr diferenciarse de la mayoría analfabeta. Tal como sostiene Alex Borucki, el ámbito revolucionario requería de un nuevo

40 Sobre la ritualidad del acto remito a la crónica de un protagonista, Juan Manuel Beruti, Memorias curiosas, Buenos Aires: Emecé, 2001, p. 80.

41 Alejandro M. Rabinovich, Ser soldado en las guerras de independencia, Buenos Aires: Sudamericana, 2013, p. 16.

42 Gaceta Mercantil, 24 de mayo de 1836, p. 2; Yaben, Biografías argentinas y sudamericanas, p. 118.

43 Sobre la política de inclusión/discriminación de los oficiales de ascendencia africana, tanto en las milicias como en el ejército regular a lo largo del tiempo, remito al libro de Andrews, Los afroargentinos, pp. 137-165. 
liderazgo: el letrado negro, y en el nuevo escenario republicano no había muchos intermediarios con esa educación. ${ }^{44}$ La calidad de letrado de Manuel manifiestamente lo distinguía del conjunto y también en este caso, como expresa Borucki, había sido el amo la entrada más común en la alfabetización.

En los años que siguen, Manuel participó y se destacó en varias acciones militares en defensa de la ciudad, recordándose su labor cuando el asedio de la flota que el virrey De Elío envió desde Montevideo el 15 de julio de $1811 .{ }^{45}$ Manuel Barbarín recibió por esta acción los despachos de capitán de la 2da compañía de fusileros del Batallón Cívico de "Pardos y Morenos libres" de reciente creación. ${ }^{46}$

Paralelamente a esta creciente militarización que se daba en toda la sociedad, los sucesivos gobiernos criollos introdujeron una serie de innovaciones de índole política y social. En 1812 se prohibió la trata de esclavos y en 1813 se aprobó la Ley de Libertad de Vientres, liberando gradualmente a los niños nacidos de madres esclavizadas. Las necesidades de la guerra llevaron también a que el gobierno iniciase en 1813 una serie de "rescates" por el cual se requería que los propietarios vendieran al Estado a sus esclavos, quienes pasaron a ser considerados "libertos" y a los cuales se les prometía la libertad luego de servir varios

44 Borucki, De compañeros, p. 244. Aquí se puede vincular la figura de Manuel Barbarín con la de Lorenzo Barcala, el líder negro unitario exaltado por Sarmiento, y Domingo Sosa, el militar que ocupó una banca en la legislatura de la provincia de Buenos Aires cuando ya habían cesado las guerras civiles. Los tres militares afrodescendientes fueron casi contemporáneos, eran letrados, lucharon en la guerra de independencia del lado patriota, ocuparon posiciones de liderazgo y también alcanzaron promoción social. Las guerras civiles que vinieron a continuación los encontraron en posiciones diferentes que derivaron luego en destinos desiguales en sus vidas. Véase al respecto Andrews, Los afroargentinos, pp. 151-156; Orlando Gabriel Morales / Luis César Caballero, "Movilidad social de los afromestizos movilizados en la independencia y las guerras civiles en el Río de la Plata. Lorenzo Barcala (1795-1835)": Historia y Memoria, 16 (2018), pp. 89-123. En el espacio rioplatense también se puede hacer una vinculación con Jacinto Molina quien se convirtió en uno de los primeros letrados negros del Uruguay independiente. Borucki, De compañeros de barco a camaradas de armas, pp. 232-241.

45 Gaceta de Buenos Aires, 18 de julio de 1811, n 58, p. 829.

46 Gaceta Mercantil, 24 de mayo de 1836, p. 2; Yaben, Biografías argentinas y sudamericanas, p. 118. 
años en el ejército. ${ }^{47}$ Las políticas de reclutamiento directo de esclavos continuaron durante las siguientes décadas hasta la abolición final de la esclavitud en 1860

Fue por esta vía de alistamiento de libertos que otros esclavizados de propiedad de Juan Barbarín fueron reclutados en los ejércitos patrios. Uno de ellos era Tomás Barbarín, natural de la costa de Mina, de treinta años, rescatado el 4 de junio de 1813 para servir en el regimiento Batallón $n^{\circ} 7$, en calidad de soldado, por cinco años. Como no supo firmar hizo la señal de la Cruz.48 Junto con él estaba José Manuel Barbarín, natural asimismo de Mina, de 28 años, de estado soltero. Fue rescatado el mismo día para servir también en este Batallón $\mathrm{N} 7$. Tampoco sabía firmar por lo que hizo la señal de la cruz. ${ }^{49}$

Sobre esta participación no he podido avanzar en tanto la documentación relevada no me permite conocer si estos esclavizados fueron contemporáneos a Manuel Macedonio o si fueron comprados con posterioridad. Obsérvese que ninguno de los dos sabía leer y escribir, situación que no resultaba extraño a la luz de los sucesos ocurridos en el año 1795. Se puede suponer que luego de los meses vividos en la cárcel, Juan Barbarín tomó conciencia de la amenaza que había significado instruir en las primeras letras a su criado Manuel. Aunque también esta circunstancia podría obedecer a las desiguales utilidades que tenía la mano de obra esclavizada y a las diferentes estrategias de los propietarios respecto a la misma. Claramente Manuel estaba llamado a ser el delegado principal del comerciante francés en Buenos Aires.

De modo que Tomás y Juan Manuel, como otros miles de exesclavizados, permanecieron como soldados en los batallones de libertos. Juraron la independencia del país en Tucumán y se comprometieron a defender la libertad "hasta con la vida", otorgada por el Soberano Congreso en las Trancas el 21 de julio de 1816.50 Tomás, incluso, continuó en el ejército de línea hasta por lo menos 1820, momento en el que lo encuentro revistando en el Batallón 2 de

\footnotetext{
47 Alejandro M. Rabinovich, Ser soldado en las guerras de independencia, p. 41.

48 Filiaciones, AGN, III, 59-1-2.

49 Ibidem.

50 Filiaciones, AGN, III, 59-1-2.
} 
Cazadores, unidad conformada en su mayoría por descendientes de africanos. ${ }^{51}$

Mientras tanto Manuel Macedonio, como asimismo un sector importante de afrodescendientes libres, continuó su carrera en las milicias cívicas de Buenos Aires, en el denominado tercio Cívico que reunía a los sectores de pardos y morenos residentes en la ciudad, y que habían sido reorganizados en 1815 de acuerdo a la espacialidad urbana y a la diferencia racial. Se ubicaban donde hoy se encuentra la denominada 'Manzana de las Luces'. El primer tercio agrupaba a la gente del centro de la ciudad; el segundo, a pobladores de los barrios más alejados — como San Nicolás, Retiro, el Socorro, La Piedad-y el tercero, a pardos y morenos libres que residían sobre todo en Monserrat, Concepción y también en el Alto de San Pedro Telmo. Las milicias cívicas, a diferencia del ejército regular, no tenían un servicio activo, sino que debían prestarlo solo cuando el Cabildo consideraba que la ciudad estaba en peligro. Allí hacían repicar sus campanas y enarbolaban una bandera y los milicianos activos debían dirigirse a sus respectivos cuarteles. ${ }^{52}$

La historiografía sobre la independencia sugiere que el proceso de militarización habría precedido y empujado a la politización de la plebe y a un ciclo de episodios "tumultuosos" que primero se desarrollaron en la ciudad y luego en la campaña. En ellos, no solamente se evocaba un estado de conmoción, de motines y alborotos, sino que había un desafío público a la autoridad. ${ }^{53}$ Una investigación militar realizada en febrero de 1819 se refiere a un motín promovido por los cabos y sargentos del tercio de Cívicos de la ciudad donde revistaba como capitán Manuel Barbarín. ${ }^{54}$ El motivo: la resistencia a cumplir la orden del Cabildo de

51 Ibidem.

52 Acuerdos del Extinguido Cabildo [AEC], 1927, vol. 5, p. 330. Di Meglio, ¡Viva el bajo pueblo!, pp. 136-138.

53 Raúl O. Fradkin, “Cultura política y acción colectiva en Buenos Aires (1806-1829). Un ejercicio de exploración”: Raúl O. Fradkin (ed.), ¿Y el pueblo dónde está? Contribuciones para una historia popular de la revolución de independencia en el Río de la Plata, Buenos Aires: Prometeo Libros, 2008, pp. 29-30.

54 Sumario militar, año 1819, N 957, AGN, X, 30-3-4. Véase el artículo de Gabriel Di Meglio, "Las palabras de Manul. La plebe urbana y la política en los años revolucionarios”: Raúl O. Fradkin (ed.), ¿Y el pueblo dónde está?, pp. 67-106. Para conocer más detalladamente el motín remito a Beruti, Memorias curiosas, pp. 296-297. 
marchar a la Plaza de la Victoria para que se les pase revista, debido al rumor de que podían convertirlos en "veteranos" e integrarlos a las tropas que luchaban contra las fuerzas artiguistas. Así lo explicarían algunos implicados en la investigación, el cambio de situación colisionaba con sus derechos de milicianos los cuales les permitían estar en servicio sin tener que abandonar la residencia ni sus domicilios particulares. Como medida de resistencia se convocaron en el hueco de la Concepción, que era la zona de residencia de pardos y morenos, donde fueron sorprendidos y desarmados por los cívicos de caballería $\mathrm{y}$ por otros vecinos armados. Las autoridades, mientras tanto, establecían la pena de muerte para cualquier "negro" que fuera encontrado armado. 55

De manera similar a lo ocurrido veinticuatro años antes en la investigación emprendida por Álzaga, en esta oportunidad se llevó a cabo también una investigación en la cual declararon obreros y artesanos de la ciudad, que eran a la vez soldados, cabos y sargentos del referido cuerpo. A los testigos se les preguntó si conocían sobre la fuga del "negro" Raimundo Vianao cuando lo apresaron al "negro" Santiago Manul acusado de ser uno de los principales cabecillas. Don Pedro Lezica declaró haber visto a un "negro" velero y cojo que se distinguía en sus gritos y amenazas a los "blancos" y que exhortaba a los "negros" a que muriesen en defensa de su causa, hablando mil iniquidades del gobierno y demás autoridades. ${ }^{56}$ En su declaración, don Anastasio Sosa, capitán de la compañía de granaderos del mismo cuerpo, afirmó que todos hablaron con respeto a la autoridad menos el granadero Pedro la Rosa quien había insultado al comandante del cuerpo, diciéndole "mulato indecente". 57

Las expresiones de los testigos y responsables dicen tanto de la intensa politización de la vida popular como de las tensiones raciales que éstas conllevaban. ${ }^{58}$ Los "negros" armados constituían un peligro y la percepción de una animosidad con los "blancos" contribuyó a hacer más conflictivo el episodio. El riesgo de un movimiento racial muy

55 Di Meglio, ¡Viva el bajo pueblo!, p. 194.

56 Sumario militar, AGN, fs. 16 y 31.

57 Ibidem, fs. 57 y 58.

58 Di Meglio afirma que una acción colectiva protagonizada y dirigida solo por plebeyos era un rasgo inédito en la ciudad de Buenos Aires. Di Meglio, ¡Viva el bajo pueblo!, pp.174-175. 
probablemente incidió para que algunos vecinos se unieran a las tropas de caballería con la finalidad de desarmarlos. Aquí se entrevé —como en la investigación anterior de 1795- una "negritud racial alternante", que se activa en contextos percibidos como intimidatorios o peligrosos. En tales circunstancias, tanto los testigos como los sospechosos pasan a ser "negros", independientemente de la condición, procedencia y el color. Como he observado en el apartado anterior, el término "negro" que tenía una connotación negativa en el periodo colonial y era casi sinónimo de esclavo, perderá fuerza durante la primera y segunda década republicana, pero seguirá aplicándose como un genérico de todos los sujetos de ascendencia africana en contextos específicos de alterización racial: de amenaza, fugas, conspiraciones, incluso para denotar extranjería.

Manuel Barbarín, si bien no fue convocado como testigo, no pudo desconocer estos hechos. No solamente porque se desempeñaba como capitán del cuerpo de cívicos, sino porque además estos ocurrieron muy cerca de la parroquia donde él vivía con su familia y, como ya se dijo, donde tenían sus viviendas la mayoría de la 'población de color' de la ciudad. Dicha zona, que constituía el sector Sud-Sudoeste de la parroquia de Concepción y Monserrat, luego pasó a llamarse el "Barrio del Tambor" porque era el preferido del sector afrodescendiente. Estos por razones sociales y económicas tendían a ubicarse en la periferia de la ciudad, junto a una treintena de las llamadas "naciones" o "asociaciones africanas" que también habían obtenido terrenos en la zona para sede de sus respectivas organizaciones. ${ }^{59}$

En el referido espacio del Tambor, las fuentes de archivo son reveladoras de una serie de tensiones sociales que igualmente tienen como protagonistas a varones y mujeres de ascendencia africana. Las mismas fricciones parecen ser una derivación de la erosión de la esclavitud y de la militarización de los varones adultos que se irían traduciendo en un cambio paulatino en las relaciones de género. El acceso a la libertad y la nueva jefatura de hogares, de parte principalmente de las mujeres, habría desencadenado en un dinámico movimiento inmobiliario del sector afroporteño libre. Miguel Ángel Rosal ubica este movimiento en la década de 1820,60 precisamente

${ }^{59}$ Rosal, Africanos y afrodescendientes, pp. 84-87.

60 Ibidem, pp. 90-91. 
cuando Reid Andrews verifica el aumento de la frecuencia de las mujeres adultas que adquiere la libertad. ${ }^{61}$

En la ciudad, la escasez habitacional y los precios altos de los terrenos y alquileres fueron llevando a la paulatina subdivisión de los mismos y a la venta de pequeños sitios. Según los datos que presenta Lyman Johnson, la vivienda desde finales del periodo colonial se había convertido en un componente en extremo importante y muy oneroso en el costo de vida. Solo una minoría era propietaria de su casa y la vasta mayoría alquilaba habitaciones o, en muchos casos, abonaba una suma en la parte trasera de los talleres. Durante el periodo republicano, esta situación se vio agravada incluso por el incremento de los alquileres de viviendas y a la reducida disponibilidad habitacional.62

La revisión del Fondo del Tribunal Civil en el Archivo General de la Nación revela una serie de conflictos por linderos y mojones, que por lo general se resolvían en juicios sumarios o ejecutorios. Aquí me voy a detener en un expediente judicial de apelación promovido por el mismo Manuel Barbarín, cuya lectura resulta inestimable para conocer las intersecciones que surgen en el estudio entre las relaciones plebeyas, las identidades sociales y las de género en la era de la emancipación. En el transcurso del año 1827, el matrimonio Barbarín llevó adelante tres juicios sucesivos con algunas vecinas por desacuerdos en las medidas de los terrenos ubicados en las calles Chile, San José y México, colindantes a su vivienda. En la primera de ellas, Simona Sarratea, en calidad de "morena libre y mujer legítima del Capitán de Pardos, Don Manuel Barbarín y con la venia de éste", eleva una queja contra la "morena" Ricarda Nogueira. ${ }^{63}$ La lectura de la fuente judicial nos retrotrae al año 1815 cuando el matrimonio Barbarín compró el terreno situado en el cuartel ${ }^{\circ} 26$, en la esquina de las calles Chile y San José, a don Francisco Belgrano, dueño de toda la cuadra.

A los efectos de la venta, se dividió la cuadra de 140 varas en cuartos de tierra, es decir en terrenos que tenían 17 1/2 varas de frente, que era la medida más común para la época y significaba un poco más de 15

\footnotetext{
61 Andrews, Los afroargentinos, p. 63.

62 Johnson, Los talleres de la revolución, pp. 251-253.

63 Manuel Barbarín por apelación, AGN, Tribunal Civil, 1827, Legajo 5, f.1.
} 
metros de largo y 50 de profundidad. 64 Dicha partición produjo varios entredichos con y entre vecinos que reclamaban una medición diferente. Uno de ellos enfrentó a Simona con Ricarda Nogueira y tuvo un pico de tensión el 20 de julio de 1831 cuando las dos mujeres, que ya habían tenido varias reyertas, se tomaron a golpes en la vereda, según el informe del jefe de policía de la ciudad.65 Está claro el carácter plebeyo de estas relaciones, pues, parecen anticiparse a las peleas de conventillo, que supo mostrar la literatura de sainete de fin de siglo XIX y principios del XX.

El segundo conflicto ocurrió con la "morena" María Joaquina, quien en 1826 compró un terreno vecino a los Barbarín y, según los dichos de Simona, aquella rompió la armonía que había reinado en la cuadra durante más de diez años. ${ }^{66}$ Aquí aparece en escena Manuel Barbarín, en calidad de "Capitán de Pardos" y "marido legítimo de Simona Sarratea", para solicitar la comparecencia de María Joaquina a juicio verbal, en tanto aquella no solo no respetaba la línea divisoria de los fondos de la calle México, sino que además había injuriado a Simona. 67 Por último, un tercer litigio enfrentó al matrimonio con don Lino Latorre por un terreno que le había comprado al "moreno" Félix Fonseca en la calle Chile. Este caso se resolvió a favor de Manuel y Simona, porque se comprobó que había sido el "moreno" José Vidal quien le había tomado nueve cuartos de los que tenía edificado. 68

La lectura atenta del expediente me permite entrever que al término de la segunda década revolucionaria los varones y mujeres de ascendencia africana vivían el impacto de una realidad compleja, cuyas manifestaciones se daban en los distintos planos de la vida social. La militarización de la sociedad no solamente representaba una amplia movilización de la población masculina adulta, sino que, tal como ha sostenido Halperín Donghi, tendría efectos duraderos en los modos de

\footnotetext{
64 Una vara medía 0,8666 metros en la región. Sobre las unidades de medidas, véase Juan Carlos Garavaglia / Pierre Gautreau (eds.), Mensurar la tierra, controlar el territorio. América Latina. Siglos XVIII, XIX, Rosario: Prohitoria, 2011, p. 29.

65 Informe sobre lo ocurrido entre las pardas Ricarda Nogueira y Simona Sarratea. Policía, AGN, X, 33-1-4, Leg. 1, 1831.

66 Manuel Barbarín por apelación, AGN, f. 2.

67 Manuel Barbarín por apelación, AGN, f. 6.

68 Ibidem, f. 16.
} 
sociabilidad en el conjunto de la población. ${ }^{69}$ De acuerdo al presente estudio, los efectos de la militarización y de la erosión de la esclavitud suponen considerar nociones de género. La ciudad porteña se había caracterizado por tener una población joven y muy masculina debido a las continuas corrientes de migrantes internacionales, regionales y también de la mano de obra esclavizada. Los censos coloniales dan cuenta del predominio cuantitativo de los varones sobre las mujeres. Este desequilibrio en 1810 se revelaba también en el conjunto de la población afroporteña en el que la cantidad de hombres por cada cien mujeres era de 108 en 1810. Hacia 1827 el índice había variado considerablemente alcanzando solamente el 68,5 , como consecuencia de la amplia movilidad, militarización y mortalidad de la población masculina adulta. ${ }^{70}$

A las mujeres que lograron paulatinamente salir del estado de esclavitud, las encontraremos en el centro de los cambios, luchando como jefas de hogar y trabajadoras, así como propietarias de inmuebles y madres de familia.

Aquí se vislumbra además una injerencia de la militarización en la configuración de las identidades sociales, tanto individuales como colectivas. La pertenencia y el grado que revisten en el escalafón militar siempre serán resaltados por los sujetos en los distintos planos de la vida social. Recordemos cuando Manuel Barbarín presenta sus escritos ante la justicia civil. Como lo expresa Alex Borucki,

"la participación en las milicias coloniales y el ejército republicano se convirtió en parte de la 'caja de herramientas' apropiada por los africanos y sus descendientes, tanto líderes como del común de la gente",

incidiendo en las identidades sociales de los descendientes de africanos. ${ }^{71}$

Los documentos de archivo trabajados en este apartado, que incluyen sumarios militares, expedientes de policía y juicios civiles, sugieren asimismo sentidos raciales contradictorios que profundizaré en el apartado siguiente.

${ }^{69}$ Halperín Donghi, Revolución y guerra, p. 141.

70 Andrews, Los afroargentinos de Buenos Aires, pp. 89-90.

71 Borucki, De compañeros, p. 274. 


\section{Manuel Barbarín y la "Patria Federal"}

Los últimos años de vida de Manuel Macedonio Barbarín coinciden con el proceso conocido como la 'Santa Federación' que encarnó Juan Manuel de Rosas. Este asumió el 1 de diciembre de 1829 cuando la Sala de Representantes de la provincia de Buenos Aires lo eligió como gobernador, y en el mismo acto le otorgó todas las facultades ordinarias y extraordinarias. En 1832 cuando terminó el primer mandato, se alejó del gobierno y lo retomó en 1835, oportunidad en la que asumió con las Facultades Extraordinarias y con la Suma del Poder Público hasta 1852.

Durante esta etapa, las posibilidades de intervención de los sectores afroporteños en la escena pública se profundizaron, lo mismo que el papel del ejército y de las milicias. Varones y mujeres, esclavizados, libertos y libres fueron interpelados desde el gobierno principalmente a través de la prensa, como lo demuestran algunas publicaciones en la década del 1830, lo que evidencia la significación que se les atribuía en la lucha política. ${ }^{72}$

Manuel Barbarín, como federal decidido, logró durante los primeros años de gobierno — que coinciden con sus últimos años de vida- un

72 Si bien la asociación Rosas/negros no habría sido tan simplemente favorable ni tan unánime, hay que destacar el papel fundamental que tuvo la prensa escrita para interpelar a los sectores afroporteños durante la crisis de 1833 y 1835. Esta acción evidencia la significación que se les atribuía desde el poder al sector afro en el conjunto de las prácticas ciudadanas, como del carácter constructivista del régimen de Rosas. El liderazgo de éste no se habría dado de manera automática, sino que fue sido necesario disputar la adhesión de las clases populares. Una pluma principal en este sentido fue la de Luis Pérez, escritor tucumano, quien creó varios periódicos destinados al mundo popular, como "El Negrito" y "La Negrita", en los cuales se apelaba concretamente a los sectores negros porteños, a quienes presentaban como los editores de tales publicaciones. La escritura de Pérez resultaba claramente distintiva por el lenguaje y la utilización de varios recursos, como ser la forma de hablar de los paisanos y de la comunidad afroporteña, recurriendo para ello a la lengua bozal, que remitía a las raíces africanas. Sus escritos contenían además cartas de lectores, algunas verdaderas y otras ficticias que pertenecían a personajes populares, entre ellos a morenas y negros de las naciones. Ver: Raúl O. Fradkin / Jorge Gelman, Juan Manuel de Rosas. La construcción de un liderazgo político, Buenos Aires: Edhasa, 2015, pp. 304 y 436; María Agustina Barrachina, La relación entre Rosas y la población afroargentina. Una aproximación a través del discurso de la prensa, Buenos Aires: Universidad de Buenos Aires, 2016, pp. 63,140-141 (Tesis de Licenciatura). 
significativo protagonismo en tanto tuvo a su cargo importantes tareas de responsabilidad política y militar. Durante la década de 1820 había ascendido en el escalafón militar provincial y en la siguiente llevó adelante la reorganización de los cuerpos de milicias de infantería de la capital, compuesta por el Batallón de Defensores de Buenos Aires, un batallón constituido especialmente por descendientes de africanos y por el Batallón de Libertos, creado en 1831 por Rosas. En 1832 ascendió al cargo de Sargento Mayor y luego integró la Plana Mayor del Ejército en calidad de "Comandante en comisión de la compañía de artillería del Batallón de Defensores de Buenos Aires". Obtuvo su última promoción como resultado de las acciones en defensa de Juan Manuel de Rosas en 1833. En reconocimiento a su actuación en los sucesos de 1833 Revolución de los Restauradores que lograron el retorno de Rosas al poder - fue promocionado al cargo superior de Teniente Coronel de regulares y segundo jefe de los Defensores de Buenos Aires, por despacho del 22 de abril de $1835 .{ }^{73}$

De tal modo, al final de su carrera alcanzó una importante promoción militar en el ejército federal, el cual constituía una mixtura entre las milicias tradicionales y el ejército regular de la década anterior. Barbarín fue uno de los oficiales afroporteños que Rosas encumbró en el podio de la patria federal y esta habilitación representaba un elemento de cohesión y atracción para los sectores negros. Podemos imaginar que Manuel con este ascenso había llegado al cenit de su carrera militar y de promoción social. Su vida en el ejército culminaba con un reconocimiento al que accedieron muy pocos afrodescedientes, y en paralelo había conformado una numerosa familia y obtenido algunos logros sociales y materiales.

Estos diferentes planos de sustentabilidad social se pusieron de manifiesto cuando se produjo su fallecimiento. Manuel Macedonio Barbarín murió el 4 de marzo de 1836, a los 55 años de edad y luego de padecer una larga enfermedad. ${ }^{74}$ Con este motivo, en la prensa local se realizaron varias publicaciones en las que se resaltaban sus méritos y dignidad. Todas fueron escritas en la Gaceta Mercantil, uno de los

73 Secretaria de Rosas, AGN, X-25-3-1. Despacho del Gobierno de Buenos Aires al Sargento Mayor de Infantería D. Manuel Barbarín.

${ }^{74}$ Según el cronista del diario: "Una enfermedad aguda cuyas particularidades son demasiadas públicas lo arrebató del seno de su familia y dentre un Pueblo que amaba y había siempre defendido." La Gaceta Mercantil, 24 de mayo de 1836, p. 2. 
principales diarios del periodo, y como era de suponer, afecto al gobierno de Rosas. En el primero de ellos, del día 7 de marzo, junto a la noticia del fallecimiento, se destacaron los importantes servicios militares prestados y su decidida adhesión a la causa federal. ${ }^{75}$ Una semana más tarde, se publicó en forma anónima una "Canción fúnebre a la sensible muerte del benemérito teniente coronel D. Manuel Barbarín". ${ }^{76}$ En el tercer escrito, el 24 de mayo, se efectuó un recorrido y exaltación de su vida y de su carrera. El redactor recordaba "los talentos, el valor y el honor" y la gran pérdida que su muerte significaba "para el pueblo" y "para su familia" que lo lloró desconsoladamente. Como el mismo redactor valoraba, esta trayectoria cobraba sentido en "un hombre de las circunstancias de Barbarín", quien había llegado desde África en calidad de esclavizado hacía un poco más de cuarenta años atrás. ${ }^{77}$

Estas circunstancias se habían modificado de manera manifiesta durante los últimos años. La viuda y sus siete hijos no escatimaron recursos para visibilizar estos cambios y el funeral fue la oportunidad para exponerlos. Tres avisos destacados, de igual tenor de los que realizaban las familias de la elite porteña, aparecieron en la misma Gaceta Mercantil, en los cuales la viuda y sus hijos participaban del deceso e invitaban al funeral. ${ }^{78}$

En esta ocasión, Simona Sarratea despliega una serie de acciones que la exhiben como una mujer decidida y sobre todo predispuesta a exponer la promoción social de la familia y el lugar que había llegado a ocupar en el entramado del poder federal. Con gran celeridad realizó una serie de solicitudes con la finalidad de lograr la pensión militar que le correspondía en carácter de viuda y de acuerdo al reglamento del Monte Pío militar. ${ }^{79}$ La primera de ellas estuvo dirigida a las autoridades religiosas de las parroquias porteñas para que certificaran los distintos

75 La Gaceta Mercantil, 7 de marzo de 1836, p. 2.

76 La Gaceta Mercantil, 14 de marzo de 1836. P. 2.

77 La Gaceta Mercantil, 24 de mayo de 1836, p. 2.

78 Los avisos de la familia Barbarín fueron publicados en la Gaceta Mercantil el 5 de marzo, 28 de mayo y el 30 de mayo de 1836.

79 El Monte Pío Militar era un fondo o depósito de dinero formado ordinariamente con autorización del Gobierno y previa la aprobación de sus estatutos, con los descuentos que se hacían a los individuos de algún cuerpo o clase o por contribución de los mismos para las pensiones a sus viudas o huérfanos. 
eventos sacramentales correspondientes a la familia a lo largo de los años. Se incluía aquí una copia de la partida de matrimonio realizado en 1805.80 También de parte del cura vicario de la iglesia de Concepción obtendría una copia de las cuatro partidas de bautismos de sus hijas menores de edad y el acta de defunción de su marido. ${ }^{81}$

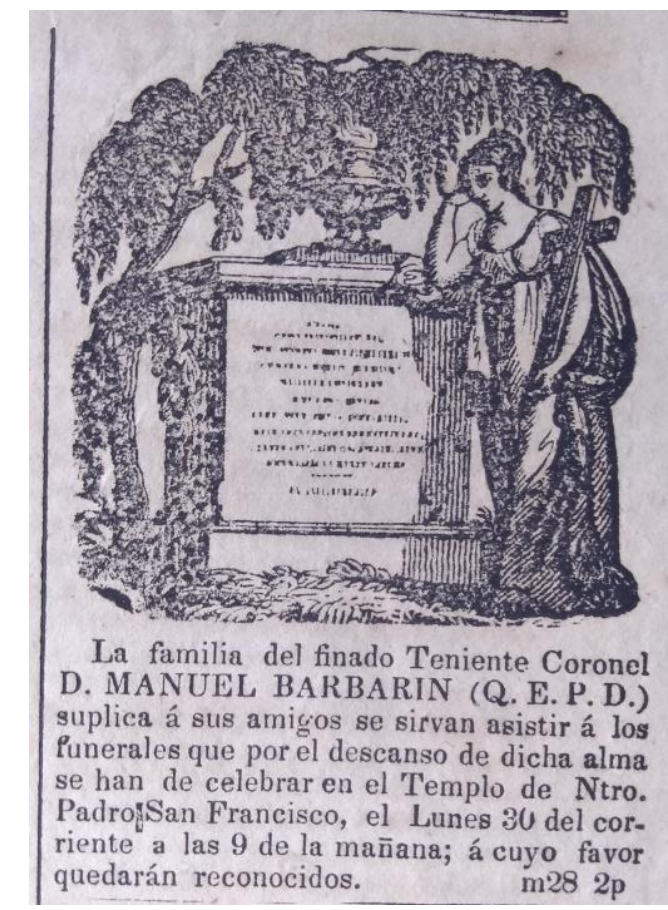

La Gaceta Mercantil, 28 de mayo de 1836.

Una vez cumplidos estos trámites, la familia se abocó a organizar el funeral público, para el cual recibió la suma de 500 pesos de parte del Superior Gobierno. ${ }^{82} \mathrm{~A}$ tales fines se contrató un funeral en el convento de San Francisco, que incluía oficios de coro y altar "con toda solemnidad". Se publicaron tres avisos en la prensa y se enviaron 100

80 Secretaria de Rosas, AGN, X-25-3-1. Copia del acta de matrimonio, 9 de abril de 1836, fs. 40-41.

81 Secretaría de Rosas, AGN, X-25-3-1. Iglesia de la Concepción, 9 y 11 de abril de 1836.

82 Manuel Macedonio Barbarín, sucesiones, n 3930, AGN, año 1838, f. 21.

Jahrbuch für Geschichte Lateinamerikas | Anuario de Historia de América Latina 
esquelas de invitaciones. Todo ello les originó un gasto de 1.700 pesos, 83 el cual, puesto en relación, significaba más de tres veces del dinero otorgado por el gobierno, casi un cuarto del valor de la vivienda familiar y 10 sueldos de Barbarín como teniente coronel, tal como surge de la pensión otorgada a la viuda al año siguiente. ${ }^{84}$

Dos años más tarde, en la sala del juzgado de la ciudad, Simona se presenta en calidad "de viuda del finado Teniente Coronel Don Manuel Barbarín" para solicitar la administración de los bienes y un adelanto de 1.000 pesos de la herencia que su marido le había dejado a la familia. De acuerdo al escrito, la muerte de su esposo le había originado gastos de consideración, siendo el más importante el referido funeral que le significó un poco más del cincuenta por ciento del dinero que le hubiese correspondido a ella en herencia. A tales fines, Simona solicita el permiso para vender la vivienda familiar valuada en un primer momento en 9.630 pesos. ${ }^{85}$ Finalmente el precio se redujo y el terreno será estimado en 2.625 pesos y la casa en 4.900 pesos. ${ }^{86}$ El detalle de las condiciones materiales de la familia Barbarín - y la significación que tienen los gastos del velatorio en el conjunto de los bienes heredadossostiene la necesidad que tuvo la familia de visibilizar el ascenso social que habían logrado en los últimos años.

En relación, a cuáles eran los elementos que legitimaban la integración y promoción social de Manuel Barbarín tenemos aquí varios elementos para destacar. Este y su familia conformaban el colectivo heterogéneo de la gente de color de la ciudad, vivían en la parroquia de

83 Manuel Macedonio Barbarín, sucesiones, AGN, año 1838, f. 31.

${ }^{84}$ La pensión otorgada será de 49 pesos y $5 / 4$ reales que significaba la cuarta parte del sueldo que le correspondería como teniente coronel. AGN, X, 25-3-1, 23 de mayo de 1837.

85 Manuel Macedonio Barbarín, sucesiones, AGN, año 1838, f. 54. El terreno tiene dos frentes Norte y Oeste. La casa presenta una estructura bastante común para la época: dormitorios y cocina tienen techos de paja, pero presenta detalles que son realzadas por artesanos de la ciudad. Por ejemplo, marcos de madera en las puertas y herrajes en la puerta de entrada y en las ventanas.

${ }^{86} \mathrm{~A}$ la viuda le corresponde la suma de $2.734,6$ pesos, y esta cede voluntariamente 1.072 pesos en beneficio de los cuatro hijos menores por la pérdida ocasionada en la venta de la casa a un precio menor del mercado. Para tener una referencia del valor del dinero veamos los sueldos mensuales de algunos profesionales y empleados en 1836. El Contador General cobra 500 pesos; oficial de libros, 250 y el alcalde, 333,3. AGN. X-16-8-6. Solicitudes, hospital de niñas, beneficencia. 
Concepción en el barrio del Tambor, junto a una mayoritaria población afroporteña tal cual surge del expediente analizado en el apartado anterior. Manuel era un igual, de acuerdo al origen y a la alteridad del colectivo "blanco", pero a la vez diferente seguramente de una mayoría ya que había logrado a través del tiempo mejorar sus condiciones sociales, materiales y culturales. No nos olvidemos de su posición de jefe de familia legítima y de su condición de letrado, que también se extendía a sus hijos. Sumado a sus logros y merecimientos en su calidad de alto oficial de milicias, ciudadano en armas y federal comprometido, que lo ubicaba desde el punto de la clase en una situación de superioridad frente a otros muchos afroporteños libres que padecían dificultdes para conseguir un trabajo y acceder a la vivienda, que eran mayoritariamente analfabetos y que tenían además impedimentos de formar y mantener una familia 'legítima', tal como nos muestran los altos índices de ilegitimidad de los registros de bautismos durante este periodo. ${ }^{87}$

Si bien todo indicaría que el tiempo contribuyó a legitimar la posición social de Manuel Barbarín, no habría dudas de que la misma terminó de consagrarse con la interacción con el poder político federal. De ser un "capitán de pardos" en el 3er Batallón de la "Legión Patricia" durante la década anterior, pasó a ser en los últimos años de su vida una figura central en el entramado militar del gobierno de Rosas. La pertenencia a las milicias urbanas ${ }^{88}$ - señalada en cada una de las presentaciones que realizaron Manuel y Simona ante la justicia civil- le habría proporcionado a aquél una identidad y promoción social diferenciada que se habría consolidado durante los últimos años de su vida.

Esta circunstancia referida a la consolidación de un estatus ascendente en la sociedad porteña de la época por parte de Barbarín merece un examen pormenorizado. Para avanzar en el análisis resulta necesario explorar en las clasificaciones eclesiásticas de la parroquia de la Concepción donde fueron bautizados sus nueve hijos a lo largo de veinte años: la primera en 1815 y la última en 1835. Siete de ellos sobrevivieron y tres se casaron antes del deceso de su padre. Considerando las circunstancias descritas, me preguntaba de qué manera habían sido anotados los hijos de Manuel y Simona en las actas parroquiales, considerando el rol que había tenido la iglesia en la

87 Manuel Macedonio Barbarín, suceciones, AGN, año 1838, f. 54.

88 Desde el 2 de marzo de 1821 era capitán del 3er Batallón de la "Legión Patricia”, que correspondía las milicias de infantería de la ciudad. 
producción de las identidades raciales desde la vida colonial. Rastreando los bautismos de los hijos Barbarín-Sarratea encuentro que los siete curas vicarios o sus ayudantes que los inscribieron durante dos décadas no dejaron de agregar en ningún caso la condición de "morenos" de los padres. Incluso en la primera de ellas éstos aparecen como "negros libres" de la misma manera que en el acta de matrimonios en 1805. En la partida de José Manuel Mamerto, en 1819, el padre figura con el cargo militar y con el agregado del don como: "Capitán don Manuel Barbarín", "moreno libre". 89

Por estas razones me planteo un nuevo interrogante en la búsqueda de reconocer cómo se entrelaza la promoción social alcanzada por Manuel Barbarín y la reiteración del agregado racial. Una primera cuestión estaría vinculada con el ámbito en el que se produce la clasificación, es decir en el ámbito de la producción de la diferencia. Me refiero a quiénes clasifican y para qué se clasifica; asimismo, en qué contexto se realiza la clasificación e incluso cómo intervienen los clasificados. ${ }^{90}$ No resulta una casualidad verificar que las categorías raciales persistieran en la esfera eclesiástica, en tanto esta institución

89 Año 1815: Nace en la Iglesia de la Purísima Concepción de Buenos Aires, María del Rosario Prudencia Barbarin, hija legítima de Manuel Macedonio Barbarín y Simona Sarratea, negros libres. Año 1818: Nace Isidora Genoveva, hija legitima del Capitán Manuel Barbarín y de Simona Sarratea, morenos libres. Año 1819: Nace Manuel Mamerto Barbarín, hijo legítimo del Capitán Don Manuel Barbarín y de Simona Sarratea, morenos libres. Año 1821: Nace Catalina, hija legítima del Capitán Manuel Barbarín y Simona Sarratea, morenos libres. Año 1823: Nace Bernarda Tomasa Juana Barbarin, hija legítima de Manuel Barbarín y Simona Sarratea, morenos libres. Año 1827: Nace Dionisia Simona del Corazón del Jesús, hija legítima de Manuel Barbarín y Simona Sarratea, morenos libres. Año 1829: Nace Mariano Loreto, hijo legítimo de Manuel Barbarín y Simona Sarratea, morenos libres (presumo que falleció). Año 1832: Nace Juan Manuel, hijo legítimo de Manuel Barbarín, de África y Simona Sarratea de Buenos Aries, morenos libres (presumo que falleció). Año 1835: Nace Cecilia, hija legítima de Manuel Barbarín y Simona Sarratea, morenos libres. Argentina, Capital Federal, Inmaculada Concepción, Bautismos 1802-1825 y 1825-1857, en línea: https://familysearch.org/ [04-11-2020].

90 Es importante destacar que según sea el tipo de fuente en el que buscamos la información, esta presentará clasificaciones particulares no siempre coincidentes, aunque los universos que clasifican parecen ser los mismos. De allí la necesidad de interrogarse más expresamente sobre el contexto de producción de la fuente y de las lógicas clasificatorias que remiten las mismas. 
se había caracterizado por ser guardiana celosa de las jerarquías raciales y sociales desde la vida colonial. En las actas de bautismos, matrimonios y defunciones continuará habiendo supuestos "blancos", "morenos", "pardos" hasta mediados del siglo XIX y los primeros estarán siempre por encima de los segundos. Es decir, que no obstante la retórica de igualdad que primaba - al menos discursivamente- en los tiempos republicanos, de revolución y erosión paulatina de la esclavitud, persistía en algunos ámbitos la jerarquía entre grupos superiores e inferiores y se expresaba a través de las visibles marcaciones raciales.

Una segunda línea me lleva a considerar los cambios y mudanzas en torno al lenguaje racial. Me pregunto qué significaba el término moreno y pardo y a qué sistema de clasificación nos remiten. Para someter a prueba la interpretación que se presumen cuando se utilizan las categorías raciales tomaré como referencia un estudio referido a la parroquia de San Telmo basado en los registros parroquiales de bautismos, el cual considero puede extenderse para esta parroquia. ${ }^{91}$ Allí se ha verificado que las categorías raciales son englobadas a partir de 1813 en dos grandes grupos: "españoles" y "gente de servicio" y más adelante "blanco" y de "color". Dentro de estos últimos predominan solo dos categorías: las de "moreno" y "pardo". El término "moreno" alude en la mayoría de los casos a personas africanas nativas como sería el caso de Manuel Macedonio y era un eufemismo de "negro", una persona de ascendencia africana plena en el Rio de la Plata. "Moreno" suaviza el término "negro", el cual antes connotaba esclavitud y era usado por los funcionarios españoles de manera despectiva, lo mismo que "mulato". ${ }^{92}$ En cuanto a la categoría de "pardo", ésta remite a autoctonía y mestizaje -e incluso a libertad, aunque también encontramos algunos varones y mujeres esclavizadas - y sería asimismo un eufemismo de "mulato",

\footnotetext{
91 Estos datos son los primeros resultados de un amplio proyecto de investigación que estoy realizando junto al Dr. Guillermo A. Rodríguez Ortiz (Benemérita Universidad Autónoma de Puebla y el GEALA/Instituto Ravignani/UBA) denominado "La población de San Telmo a la luz de los documentos eclesiásticos desde la creación de la parroquia hasta la abolición de la esclavitud (1813-1860)". A través del mismo se relevaron los libros parroquiales (bautismos, matrimonios y defunciones) desde la creación de la parroquia hasta la abolición de la esclavitud.

92 Borucki, De compañeros, pp. 34 y 35; Andrews, Los afroargentinos, pp. 98-105.
} 
expresión racial que no aparece en ningún caso en esta fuente. Al término "negro" tampoco se lo encontrará en esta fuente durante este periodo, aunque sí se lo hallará, como ya lo vio, en repositorios judiciales, sumarios y filiaciones militares, además en los informes y archivos de policía.

Resulta importante considerar que solo una cuarta parte de los sujetos que integran "la gente de servicio" tiene una clasificación racial. La mayoría no la tiene. Manuel y Simona están dentro del primer grupo, lo que podría estar significando tanto la descripción del color y el fenotipo, como la visibilidad en la ciudad de una trayectoria. Pensemos que Manuel era un nativo africano muy conocido en la ciudad, un moreno que había sido testigo de los sucesos transformadores de las últimas décadas. Como lo señala Lyman Johnson, cuando éste falleció, el autor del obituario no vio la necesidad de detenerse en los detalles biográficos más interesantes de su vida como soldado valiente y colocó estos sustantivos logros en el contexto intencionalmente oscuro que sugieren sus palabras "un hombre de las circunstancias de Barbarín".93

En este plano de la vida social, se observa que las identidades sociales y las categorías raciales no siguen un curso lineal. Son ubicuas y contradictorias. No son fijas en un pasado esencial, están sujetas al juego continuo de la historia, la sociedad, el poder y se articulan en las distintas esferas de la experiencia social. En este punto se puede confirmar, en consonancia con la tesis de Alex Borucki, que la gestión de la propia identidad no se limitaba a lo racial, sino que expresaba una identidad social más amplia y abarcadora. En la trayectoria de Manuel Macedonio Barbarín, como en las vidas de los líderes negros, las estrategias individuales hacen intersección con los modelos de diferenciación y pertenencia. Se verifica, incluso, como lo expresa el autor, de qué manera sus historias ilustran los límites que podían lograr quienes ponían a prueba estos límites a través de su interacción con los sectores dominantes de la sociedad. ${ }^{94}$

En lo que refiere a las categorías raciales se advierte que éstas no desaparecieron, pero sí se transformaron. En el Río de la Plata, como en toda la América española, si bien la Guerra de Independencia significaría el fin de las leyes de 'castas' y más tarde la abolición de la esclavitud, esta situación no representó el fin de las marcaciones

93 Johnson, Los talleres de la revolución, p. 330.

94 Borucki, De compañeros, p. 274. 
raciales ya que los efectos de siglos de colonización y de pensamiento y de prácticas raciales de la colonia siguieron manifestándose en las políticas de las nuevas repúblicas. De allí que seguiremos encontrando clasificaciones raciales con menor o mayor grado de explicitud en una amplia variedad de fuentes documentales, tanto públicas como privadas como se ha podido verificar en el texto.

Acerca de ello cabe interrogarse más explícitamente sobre los contextos de producción de esas fuentes para tener una mayor comprensión de las formas de clasificar en tanto éstas revelan —o son indicios- de las políticas que crearon esos instrumentos y también de quienes las produjeron. La iglesia todavía 'hereda' la mirada colonial que pone mucho el ojo en la negritud porque dice mucho al respecto del origen y de la calidad de los feligreses y de la cuestión de la sangre que portaban, que siempre era discriminatoria, aunque la apariencia de la persona no lo connotara tanto. Mientras que en las instituciones estatales las reservan y las recrean para continuar marcando distinciones y jerarquías a pesar de la ideología republicana.

En parte por esta posibilidad, y a los progresos del igualitarismo resultantes del credo revolucionario durante el proceso de independencia, se introdujeron asimismo cambios en el lenguaje racial: "moreno" y "pardo" parecen reemplazar en las fuentes oficiales a "negros" y "mulatos" que conllevan sentidos más negativos vinculados a la negritud. Incluso la mayoría de los descendientes de esclavizados libres se denominaban como "moreno". No obstante, resulta importante de destacar lo que pareciera una constante: en contextos considerados de amenaza y subversión los funcionarios judiciales, policiales, e incluso políticos, continuaron utilizando el término "negro" como un genérico racial que designaba a todos los componentes mestizos de los descendientes de africanos. Esta negritud alternante que se activa en determinadas circunstancias resulta un claro ejemplo de los sentidos múltiples y polisémicos que circulan en la negritud.

De modo que el recorrido realizado en un tiempo extendido posibilita el registro de los caminos contradictorios y sinuosos que adquieren las identidades sociales y raciales en los escenarios urbanos. No resultaría una casualidad que este juego y ambigüedad ocurriese en la ciudad de Buenos Aires, en tanto la cambiante y heterogénea composición de la población porteña subvirtió y fortaleció las fronteras sociales y raciales desde la vida colonial. Aquí, una presunta conspiración destinada a 
generar una rebelión de esclavos en Buenos Aires en 1795 ofrece poderosos vínculos con los cambios económicos y demográficos que habían transformado la plebe de Buenos Aires en la década anterior. Claramente, estos cambios terminaron de profundizarse en los años subsiguientes, durante la Guerra de Independencia y luego en el gobierno de Juan Manuel de Rosas, y con ello los mecanismos de integración, alteridad y promoción social de los descendientes de africanos, tanto de los varones como de las mujeres.

Jahrbuch für Geschichte Lateinamerikas | Anuario de Historia de América Latina 